\title{
The Maintenance of Celestial Burial in Ngari Tibetan Area: Theoretical Debates and the Interview Study
}

\author{
Qingyang $\mathrm{Hu}^{1, *}, \dagger$, Yingnuo Wang ${ }^{2, \dagger}$, Yuening $\mathrm{Xu}^{3, \dagger}$ \\ ${ }^{1}$ Chengdu Foreign Languages School, Chengdu, Sichuan Province, China \\ ${ }^{2}$ Xi'an Tie Yi High School, Xi'an, Shan Xi Province, China \\ ${ }^{3}$ Beijing Royal School, Beijing, Beijing Province, China \\ *Corresponding author. Email: guanghua.ren@gecacademy.cn \\ ${ }^{\top}$ These authors contributed equally.
}

\begin{abstract}
This paper discusses celestial burial, a kind of burial that is famous for its main process- let the bodies be eaten by the vultures. As an old and traditional burial, people have already performed the celestial burial for a long time, with all kinds of factors that push them to do so. This paper would mainly discuss the reason why celestial burial is still maintained today, to find out the power behind it. This paper uses the celestial burial in Ngari, Tibetan as an example to study the topic. In this paper, both library research and interviews are used. This article has concluded that celestial burial is maintained because the young generation has the sense of passing on the tradition and they have the sense of social obligation for the ritual.
\end{abstract}

Keywords: Celestial burial, Tibetan Ngari, Religion.

\section{INTRODUCTION}

Funeral plays a very important role in human society $[1,2]$. Throughout human history, the funeral is a special way for human beings to understand death. The Funeral has a unique mysterious color. Human beings know nothing about death, and the funeral is like a bridge between human beings and the unknown. In anthropology, the funeral ceremony has its unique research value. The cultural environment and religious beliefs in different regions will affect the local funeral methods $[2,3]$.

Tibet has a unique natural environment, history, and culture. Religion, culture, history, and natural factors all affect the formation of funerals in this place [4]. This paper holds that its funeral is unique and is an example of research value. Ngari Region is located on the southwest border of China, the west of Tibet Autonomous Region, and the north of Qinghai Tibet Plateau [5]. It borders Xinjiang Uygur Autonomous Region in the north, Nepal, and India in the southwest and west. With an area of 345000 square kilometers, Ngari is the second-largest prefecture-level unit in Tibet. Ngari Region has strong winds throughout the year, some areas are very cold, and the annual average temperature is less than zero. Due to its high altitude, cold and dry climate, Ngari has relatively little rainfall throughout the year, strong seasonality, and large temperature difference between day and night. And Ngari's winter is long and cold. In this special climate environment, Tibetan areas still retain a special funeral method - celestial burial $[4,5]$. This paper believes that the origin of celestial burial is closely related to this. There are also many Tibetan Buddhist temples and more than a dozen revolutionary historical sites $[2,3]$. This paper believes that this area has research advantages and takes this place as the main research site. Due to the influence of Tibetan Buddhism, a unique way of the funeral has evolved here.

Previously, many pieces of research have been studied about the history of the celestial burial, the origin of the celestial burial [1-3,6]. These studies have achieved many valuable results. Whereas the top concerns are different from this article. This paper's top concern is about the maintenance of celestial burial. This article uses library research and field research(interview) as the basis of the analysis. Celestial burial's history, relation to religion is highly related when trying to get the answer to the question, this article would discuss them separately in the later sections. Furthermore, interviews would be discussed and analyzed in the paper before the result of this paper is exposed. This paper would study why this ritual is still maintained which can provide a 
special view of how people value celestial burial and understand celestial burial changes and the power which pushes people to perform the ritual.

\section{LITERATURE REVIEW}

Bao Heping works on Cultural connotations and ecological implications of Mongolian celestial burial [7]. His paper focuses on celestial burials in Inner Mongolia. It well presents the advantages of Mongolian sky burial. The article mainly explains from three sections: origin, form, content, and the implementation of rituals, which are all affected by many different kinds of factors. This article has spent a lot of space to explain the Mongolian celestial burial to the food chain and ecological environment protection. According to the article, Mongolian people attach great importance to the environment, so relevant laws and regulations have been issued to ensure the implementation of celestial burial. Origin analysis of the natural burial customs in Tibet by Huo Wei provides views about the theories of the origin of celestial burial which bonds the ritual to religion. Scholars focus mainly on materials about natural advantages and religious parts and view them to have a basic background of the ritual topic, for instance, Unique natural burial custom in Tibet by $\mathrm{Ci}$ renjide and environmental factors analysis of the formation of Tibetan celestial burial culture by Hua Zhihai. Hua's article records the whole process of celestial burial in detail $[8,9]$. The celestial burial ceremony in Tibetan areas is basically like what was recorded in this article. The process record of this paper is very detailed, but it does not introduce the culture and history of Tibetan areas and does not put forward its complete views. The author pays more attention to records, which is useful for this article when discussing the actual process. Because of that, this article can give readers a very objective and comprehensive understanding of the process of sky burial, which is also important in the preparation of this research. The author aims to make his contribution to the development of cultural exchange and cultural blending through the study of ethnic groups such as Tibetans. This paper is very professional and has unique views on cultural exchange. In the author's eyes, today's Tibetan area is a place where Chinese culture and Tibetan culture prosper and develop together. He believes that culture should achieve mutual understanding and respect. Only in this way can it meet the basic needs of harmonious development. In general, Hua's article advocates peaceful and harmonious development [10].

Jiao Zhiping mainly studies the relationship between celestial burial and local paternal blood organizations under the influence of Tibetan history, geography, social culture, and other factors. This is a very professional and specific paper, which starts from introducing the local special social structure to vividly and concretely describing the whole process of celestial [11].
Xiong Chongqing, another Chinese scholar who studies funeral customs and Tibetan social structure uses the cultural circle theory of anthropology to explain this folk phenomenon of celestial burial and puts forward the concept of the cultural circle of celestial burial folk custom. This paper introduces and studies the concept of cultural circle, and analyzes the process and causes of the formation of Tibetan cultural circle. Finally, it points out the characteristics of the folk culture circle of celestial burial.

Most of the materials are used to provide background knowledge and the basis of the hypothesis in this research. Many of them studied celestial burial in the aspects of origination, about the environment, religion, etc. But not many studies have been done to find out the maintenance of the ritual, that is, why this ritual is still performed today, in the 21 st Century. That's why this paper is to aims to find out the main power behind the force which pushes people to perform this ritual.

\section{METHOD}

This paper would use a qualitative paradigm to understand the question as this paper would use interviews to understand the current situation of the celestial burial from a small group of people. Library research is also used as the basis of the hypothesis in the research. As for interviews, it would probably give more depth than surveys. In the interview, the questions asked about young people's understanding of the burial, the reason for attending the burial, etc. The questions are mainly about younger people's understanding of celestial burial and the process of celestial burial in more detail, to find in young generation's perspective, what is the main power in this ritual and if the processes have slightly changed over time. When discussing why celestial burial is still maintained today, this study looked into factors that might show how the celestial burial was affected, which can provide us clues about the possible important factors for the maintenance.

In the following sections, this paper will discuss the process, origin, natural advantage, religious power, and the relationship between celestial burial and Tibetan social structure. These factors are what this research considered important factors affecting the ritual.

\section{PROCESS}

The process of celestial burial is rather complex and this paper would not discuss it in so detail here in the paper. The process of celestial burial needs special people to preside over, needs specific time and place, and there are some taboos and rules before and after celestial burial. Celestial burial includes five links. [11]This paper will focus on vultures and celestial burial grounds 
First, when people begin to enter a coma, family members begin to avoid outsiders. In their ideas, strangers may bring evil Qi to the soul, destroy the transfer of the soul, and make the dying unable to die safely. Local people will put a bunch of cedar at the door, or pile cow dung in front of the tent to avoid strangers, and others will not visit when they see these signs.[3]

Second, the process begins just before the death of the person. People would whisper in that person's ears and tell him that he is free to go to another world or he should remember the Buddhism statue at heart (which is generally related to the religious belief). Then after the death, the ritual begins. It involves preparing food and drink for the dead, receiving visits from family and friends, asking the Lama to read the scriptures from morning to night to transcend the soul of the dead, pray for the soul, and many small traditions one bonds the other.

When this stage is done, the body is then taken to the celestial burial platform where the Stobs-Idan or Robshags-ba would help to separate the body and feed the body to the vultures.

The timing and direction of the funeral are very learned and need to be determined by the Living Buddha. In the evening before the funeral, every family should sprinkle ash on the door to prevent the souls of the dead from entering and abandoning worldly greed. The time of the funeral is usually at dawn. People think that the sunrise is the strongest time of the earth's energy, which can better help the soul get rid of the body. Many places in Gannan use stretchers or wooden racks to carry corpses. The corpses are placed on wooden racks. People will let the corpses sit and wrap white blankets. Funeral teams usually carry the corpses around the local temples. The order of the funeral procession is that several relatives and friends light Tibetan incense first, followed by the dead, followed by other relatives. It is worth noting that the family members do not go to the celestial burial ground.

Most of the celestial burial grounds are located on the hillside or foot of the mountain far from the city, surrounded by temples and vulture activities. Vultures are large Raptors of the ornitha class, Falconiformes and Falconidae. Vultures are regarded as divine birds and recognized by Tibetan Buddhism as the embodiment of monks. After people die, their souls can be reincarnated to an ideal place through their hands. This is also the main motive of celestial burial.

When the funeral procession arrives at the celestial burial ground, it will light a cedar mulberry fire, and vultures will gather in the celestial burial ground when they see this smoke if they know those signs already. And there are often callings and loud sounds of beating stones to attract their attention.
The vultures would then get together to eat the body. If the body is not finished by the vultures, then the family members would invite the monk to read the sutras for the dead. Generally speaking, the burial process is long and strict, and it includes tiny and specific actions people need to obey and disobey would normally relate to "bad luck for the living and the death" and "causing difficulties for the soul". Also, the process greatly relies on religion, monk and Lama. They often play important roles [11].

Next, family members will invite the living Buddha to come home for Dharma on the "49th day". Even within $3 \sim 5$ years, they will provide meals twice a year and invite lamas to chant scriptures. However, there are many taboos after burial. For example, the family does not participate in various recreational activities within a year, and can only call the dead "dead", and can not directly call the names of the dead. There are many forbidden things during the process. The reasons for the forbidden are usually related to "bringing bad luck for both the living and the soul of the dead", "causing difficulties for the souls of the dead to go to paradise" etc. In other words, the forbidden is closely related to religion and is always highly regarded and strictly obeyed. There are rules like no loud crying during the process, no combing hair, no photos or video recordings, and so on.

\section{THE ORIGIN OF THE CELESTIAL BURIAL}

The burial in Tibet did not begin with celestial burial but with inhumation. In the middle reaches of the Yarlung Maptra River, in the Yaron Valley, known as the birthplace of Tibetan civilization, the distribution of tombs is especially common. There are many ancient tombs in Tibet although most of them are not very recognizable. So, at a time, inhumation was an earlier burial system implemented in Tibet. But eventually, the inhumation's dominant place was taken by celestial burial. Not every scholar agrees with the exact point about how this ritual was formed, but usually, there are four aspects that many former scholars would consider for the formation of the celestial burial.

In this section, this paper will discuss the spiritual origin of the ritual. The exact origin of the celestial burial is discussed in many materials but the source is not very clear. The origin of the celestial burial is possibly mixed Many materials have different assumptions, and this paper lists the main cultures and religions which are mentioned commonly.

Bon believes that the God in heaven is "Zan". In the Tubo Period, the seven kings "Zanpu" were gods from heaven, so they returned to heaven after their death. Therefore, today's celestial burial originated from primitive celestial burial. The book of Tibetan King Tong Ji wrote that the seven heavenly red kings "climb the heavenly rope in turn, die and return to the heaven, and 
dissipate like a rainbow." When the Bon religion played an important role in Tibetan society, The Bon religion thought further provided a theory for celestial burial and further improved behavior.

In the Bon concept, vultures are closely related to "Qiong", which is an abstract concept and has a high status. They believe that don't hurt vultures, otherwise, bad consequences will occur. Bon believes that vultures are like a bridge connecting the world and the sky. And celestial burial is the way and process to realize ascension. Therefore, in the celestial burial culture, the vulture eating the body is the process of the soul ascending to heaven, the vulture is the sacred Messenger, and the ceremony is the process of communication.

The second related religion is Buddhism which is generally believed that vultures are sent by the Buddha to surpass everyone. It is mentioned in the doctrine of Xijie sect of Tibetan Buddhism and believes that in a natural place, natural death and dedication of one's own flesh body. The concepts of "compassion" and "reincarnation" in Buddhism also have an impact on the ritual.

The third related theory comes from local folklore in Tibet. It is said that celestial burial originates from ancient Indian customs. This view holds that sky burial is gradually developed from the wild burial in folk customs. According to some public opinion surveys, many locals also believe that celestial burial comes from India. Han Xiyu's "about celestial burial" and Huo Wei's discrimination on the origin of Tibetan celestial burial customs even put forward the theory that the stones of the celestial burial platform came from India's celestial burial platform.

The last one is Zoroastrianism that the celestial burial may have been received from ancient Central Asia. First of all, in ancient Central Asia, in the Neolithic times, there were very similar burials to the celestial Some people think that the reason related to attending the funeral is almost always related to obligation, partially just be a tradition. For local people, a funeral is a normal thing and some people believe the funeral is related to culture. They think that a funeral is a sacred process. This silent environment shows the Tibetan people's awe of death and celestial burial allows them to give back to nature. Some respondents believe that Celestial burial has no direct connection with Buddhism. The seven Kings of Tianchi (4th century BC) had celestial burial ceremonies. Tubo did not have Buddhism in this generation, and the main religion was Bon. Because of the worship of the god of heaven, the sky burial ceremony appeared.

To outsiders, celestial burial may be novel, but for locals, this is a normal traditional way of the funeral. Their attitude towards celestial burial is just like the attitude towards post-mortem cremation. Some people mentioned how this ritual is a continuation of life that death is just another beginning. Celestial funerals still have long and complex processes, some forbidden things have strictly stayed the same (the only male can attend). So far, the government has no policy on celestial burial. There was neither encourage nor blow [8]. This paper argues that for different cultures and traditions, the government has a tolerant attitude. The celestial burial customs in Tibetan areas will have some differences, but the customs in some areas are similar, and the basic ideas behind them are the same. And because of the celestial burial, vultures are better able to survive in the wild. customs in Tibet. (Supported by ancient drawings) And the tradition continued later on.

Considering the geographic location of Tibet, the communication between Tibet central Asia is not a problem. Moreover, with the expansion of Tubo efforts, it once entered Central Asia more than once and collided and communicated with local culture. So the theory goes, around the Persian Sasanid period, Bokenism became popular in Central Asia and the ritual passed to China during the Northern and Southern Dynasties. Some even mentioned that the Bon religion also shows the impact of Central Asia culture.

\section{NATURAL ADVANTAGE}

The high altitude and mountainous characteristics of Tibetan areas hinder the way of cremation. The growth of plants is relatively limited. In particular, tall plants are difficult to grow and have a long growth cycle, so it is difficult to grow lush. The forestry resources that can be used are also very limited in central Tibet. The material for cremation is then not very available.

As for water burial, although there are many lakes and rivers in Tibet areas, there are more than 20 rivers with a river basin area of more than 10,000 square kilometres, more than 100 rivers with more than 2,000 square kilometres, and thousands of rivers with more than 100 square kilometres, most lake's water is not swift quiet hard for removing the body. And the water contains salt which makes it difficult for the body to disappear. As it would take a long time to make the body disappear, the process might make the family members painful. So water burial would not be a good option either. It is mentioned above that the average altitude is more than 4,000 meters, and the temperature is low all year round. Two-thirds of the grassland is a permanent permafrost layer so it is difficult to dig tombs even in summer. So it would be a difficult task to dig for the burial and therefore not a good choice. There are also claims that as nomadic nationalities, the attachment and appreciation to the ground are not very strong for these Tibetan people as they have to move around very often to feed their horses and cows, which probably makes them quite different from farmers in the other areas of China [10]. As for celestial burial, the vulture is just the advantage. The vulture is a kind of animal that eats the dead bodies of the animals in particular. This means that they are naturally 
attracted to the dead bodies of people and would leave almost nothing when they left. The cold temperature of the plateau makes also keeps the body from rotting in a short time and this makes celestial burial easy to operate. It is not true that the natural advantage could be a very direct reason for the maintenance as people do not normally seek convenient ways to perform rituals. But as the environmental condition is very much related to some of the restrain when performing rituals, this research believes natural advantage could be a minor factor that contributes to the maintenance.

\section{RELIGIOUS POWER}

In this section, the main religious power would be discussed. Religion is usually the factor people would normally consider essential for this celestial burial. By studying the religious power, it is aimed that there would be a clearer idea of how religion affects the ritual, in which way religion "control" the ritual. Buddhism and Bon religion are the main aspects that have the power of the ritual in the religious aspect. For Buddhism, the theory of "everything has a spirit", "the spirit lasts forever", "afterlife" and "give" are beliefs that are buried in most believers in Tibet as it is mentioned by many scholars $[10,11]$. The celestial burial is a kind of activity that uses those theories as a basis and adds them into actual acts for people to perform. Therefore, it might increase the possibility for the people to choose this burial. Buddhism also changed some of the customs in celestial burial. In Bon's religion, there are many relations. Mostly have mentioned in the origin of the celestial burial. Also, the worship of "heaven" in the day burial is one of the manifestations of natural worship. Natural worship is probably a force that pushes people to perform the ritual. The religious power is mainly shown by the process as many of the processes contain meanings that correspond with the theories and beliefs in the religion. And the forbidden is also very related to religious reasons.

\section{RELATIONSHIP BETWEEN CELESTIAL BURIAL AND TIBETAN SOCIAL STRUCTURE}

Some literature shows that in some celestial burial ceremonies, the treatment methods of male and female dead will be different. On the celestial burial platform, the male deceased was in a prone position with his face down; Women, on the contrary, lean back and face up. Although it is the difference in posture, it also reflects the gender status difference. On the one hand, it reflects the dominant position of men in this culture. On the other hand, the special treatment and restriction of women show the humility of women's status. In the interview, this research found that only men can participate in the celestial burial, which is generally attended by older people. It can be seen that celestial burial also seems to be a funeral method born in the patriarchal society. Due to geographical factors, cultural convergence, and even prefecture-level division, Tibetan areas have promoted the formation of their cultural circle. Therefore, the significance of the existence of celestial burial, like the folk customs of other nationalities, is their special way [11].

In the traditional celestial burial in Tibet, women must not be buried, which is also a similar taboo in other burial methods such as water burial, earth burial, cremation, and so on. Local people may think that women's status is low, their bodies will be unclean, and they can't enter the sacred funeral ceremony place, otherwise, it will be detrimental to the reincarnation of the dead [12].

\section{INTERVIEWS}

\subsection{Process of the interviews}

In the beginning, it was not very easy to contact local Tibetans, because many areas of Tibetan are very primitive and have not been modernized due to science and technology. This research used WeChat, telephone, and other methods to contact the local people. But since there is no signal in most Tibetan Autonomous regions, it is needed to spend a long time waiting for their reply. This research toughed with Tibetans in two regions at the same time: Yushu and Ngari, to make sure that there are interviews on time. Those preparations are necessary because it is not sure whether Tibetans are willing to accept the interview. Finally, the study decided to interview Tibetans in the Ngari area. Because of their religion, they may avoid certain questions. In the interview, questions were not asked directly. When the interview started, expressions of respect and interest in their culture by chatting with them. Perhaps because of such an interview method, the Tibetan interviewed let down their guard and responded to the questions in many details (most information could not be found in the materials). When it comes to their understanding of celestial burial, they showed their opinions in kinds of different views, which played a very important role in this research.

\subsection{Findings of the interviews}

In the interviews, young people were asked (between 20-30) about their understanding of the ritual and the more detailed information and processes in their celestial burial which they still perform today. In this section, this study would first summarize the content of the interviews, then discuss this article's view about how their ideas and attitude relate to the maintenance.

About the main factor, some people mentioned obligation. One emphasizes that men have an obligation towards such ritual, kinds of people mentioned how being an adult would be the reason for attending the ritual. They 
both believed that it is the identity in their community that has the power to force them and that they should obey, and as only if the man is allowed to participate in the celestial ritual. Moreover, some people mentioned culture, saying that it is a kind of tradition that they would not question about. Within the obligation part, two people particularly mentioned the character of male adults and the long complex process people have to follow, suggesting that some of the strict rules of this ritual are kept though slightly changed. Another force of maintenance was described as helping nature. As the environment is getting worse, people believed that in this way the vulture can find more food so they are more likely to survive in the wild. This point was not found previously in the library research.

The celestial burials are also slightly different between different Tibetan areas, but as people mentioned, the basic idea is roughly the same. The meaning and the main core of the ritual hardly change as most of them suggested that it is about 'the reborn', the continuation of life. The interviewees said that death is just another beginning. All of them agreed that it is a sacred process but at the same time, it is just another normal traditional way of the funeral. To outsiders, celestial burial may be novel, but for locals, this is a normal traditional way of the funeral. When asked about the origin, some interviewees believed that the Bon religion is more related to the funeral and that Buddhism does not have direct influences. Some respondents talked about the seven Kings of Tianchi (4th century BC) who had celestial burial ceremonies. Tubo did not have Buddhism in this generation, and the main religion was Bon. This point matches the idea of this research as this article also believes the Bon religion is the main religious force. As this article considers that government force could be influential the question has asked about if the government has relative regulation towards the ritual. From the reply, it seems that the government has no policy on celestial burial. There was neither encourage nor blow. The government appears to be tolerant towards celestial burial and this attitude this article believes might also contribute to the maintenance.

Previously, it is assumed by this research in the early stages, that the reason for Tibetans to participate in celestial burial might be related to religion but it is found that this hypothesis was not tenable in the interview. From the literature, the origin of Tibetan celestial burial may be closely related to religion can be found A common phenomenon is that the emergence of religion is always accompanied by the formation of rituals, so it is not difficult to understand the relationship between celestial burial and rituals. Interviewers mentioned that there is no direct contact between ordinary Tibetan and religious leaders, and many materials do not make this issue very clear. Most of the reasons they attend funerals are because of dead people of relatives, neighbors, or even from the next village. Moreover, not all Tibetans can be buried in the sky after death. Eminent monks and masters will first determine whether the deceased has the conditions for a celestial burial. Somewhat different from the information I have found, the conditions for celestial burial are not closely related to social status, but because some bodies have taken a lot of drugs for diseases before their death. Such bodies cannot be buried in heaven. If the drugs are not very strong, the dead can still be buried in heaven. Because if the body of a dead person contains large amounts of the drug, it can damage the health of vultures. This will break the normal chain of biological. What's more, nowadays, because of the serious environmental problems, many wild animals can't find enough food to survive, Neither do vultures. But a celestial burial would provide enough food for vultures to survive, which is also a part of the biological chain.

\section{CONCLUSION}

From this research, it seems that religion and environmental conditions are very essential for the formation and continuation of the ritual. From the interview, it is found that most people consider the ritual as a tradition that needs to be performed because of the obligation of being part of the Tibetan community and being a Tibetan adult. The youngsters (20-30) the research interviewed did not emphasize how religion affects them, which suggests that the reasons for the maintenance nowadays might not be fully explained by reasons mentioned by the articles this paper researched. The older generation's reasons for performing the ritual might mainly be due to religion and environmental conditions, but the younger generation's reasons can get more complex. Therefore, this paper provides fieldresearch materials and literature background for scholars to discuss the main factors that push young people in the 21 st century to perform celestial burials.

\section{REFERENCES}

[1] Zhang Keji. (2017). On the celestial burial custom in Gannan Tibetan area. China National Expo (07), 7 8. Doi: CNKI: Sun: MZBL. 0.2017-07-016

[2] Wu Qiulin. (2019). An analysis of the cultural roots of the celestial burial ceremony in Tibet -- Also on the study of the "other side" integration between Han and Tibet. JOURNAL OF SOUTHWEST UNIVERSITY FOR NATIONALITIES (HUMANITIES AND SOCIAL SCIENCES EDITION) (11), 49-57. Doi: CNKI: Sun: xnzs. 0.2019-11-008

[3] Xia wujiaoba \& Dong Zhoujia. (2012). An analysis of the origin of Tibetan funerals. Journal of Sichuan University for Nationalities (02), 5-9. Doi: 10.13934/j.cnki.cn51-1729/g4.2012.02.009 
[4] Ying Zhen. (2016). Funeral customs and Tibetan social structure: a case study of Baiyu County, Sichuan Province. Journal of Sichuan University for Nationalities (02), 1-5. Doi: 10.13934/j.cnki.cn51$1729 / \mathrm{g} 4.2016 .02 .001$

[5] He Libo \& Zhu Puxuan. (2013). The formation and characteristics of the cultural circle of celestial burial folk custom. Journal of Shanxi Datong University (SOCIAL SCIENCE EDITION) (04), 79-83. Doi: CNKI: Sun: dtzj. 0.2013-04-021

[6] Yang Chunyao (2016). Traditional etiquette and Modernity - celestial burial etiquette. Young writer (15), 171-173. Doi: CNKI: Sun: qnwj. 0.2016-15118

[7] Bao Heping \& Jiri Gala. (2009). Cultural connotation and ecological implication of Mongolian celestial burial. JOURNAL OF CENTRAL UNIVERSITY FOR NATIONALITIES (PHILOSOPHY AND SOCIAL SCIENCES EDITION) (03), 72-76. Doi: 10.15970/j.cnki.1005-8575.2009.03.025.

[8] Ci rendeji. (2009). Unique Tibetan celestial burial customs. Legal system and Society (01), 239-243. Doi: 10.19387/j.cnki.1009-0592.2009.01.142

[9] Huo Wei Origin analysis of the natural burial customs in Tibet page 4

[10] Hua Zhihai(2010). On the environmental factors of the formation of Tibetan celestial burial culture.Journal of Northwest University for Nationalities (Philosophy and Social Sciences)(03),41-44. DOI: CNKI: SUN:XBMZ.0.2010-03-009.page 1

[11] Jiao Zhiping, Chen Changwen. (2003). On the role of geography and religion in Tibetan funeral customs.Tibet Study (03), 58-64. doi: CNKI: SUN: XZYJ.0.2003-03-009.page 2

[12] Xiong Chongxin, Tao Xiaohui.Exploration of the Origin of Creburial [J]. Studies in Tibet, 19 Mao. (4) 